\title{
Near hanging presenting to an accident and emergency department
}

\author{
M A Howell, H R Guly
}

\begin{abstract}
Victims of near hanging are being increasingly seen in accident and emergency (A\&E) departments. This paper reports on seven cases of near hanging seen over four years in a district general hospital. The mechanism of injury is ligature strangulation rather than cervical spinal cord injury. All cases of near hanging should be actively and vigorously resuscitated, as initial presenting features bear a poor correlation to eventual outcome.

(f Accid Emerg Med 1996;13:135-136)
\end{abstract}

Key terms: near hanging; strangulation

Attempted hanging may represent suicidal, parasuicidal, sexual, or attention seeking behaviour. In this paper we present seven patients seen over a four year period in the accident and emergency (A\&E) department of a large district general hospital, followed by a short discussion of the epidemiology, pathophysiology, clinical features, and management of such cases.

\section{Case 1}

A 14 year old schoolboy with no history of psychiatric problems was found by his father suspended by a rope attached to a beam in his bedroom. He had been suspended for up to 10 min with his feet almost touching the floor. The reasons for his attempted hanging were minor family upsets and bullying at school. $\mathrm{He}$ was immediately cut down and was unconscious, unresponsive, blue, not breathing, with a weak, rapid pulse. Mouth to mouth ventilation was started and continued in spite of the patient vomiting.

On arrival of the ambulance he was breathing spontaneously and had a Glasgow coma scale (GCS) score of 3. He was not maintaining a good airway so was intubated. However he pulled the endotracheal tube out before arrival at hospital. On arrival his GCS score was 3 and again he had a poor airway so he was paralysed and reintubated. On examination there was a rope mark around the neck with some facial mottling but neither petechiae nor subconjunctival haemorrhages. A cervical spine $x$ ray and computerised tomography scan of his head were normal. A chest $x$ ray confirmed that aspiration had occurred.

The patient was treated on the intensive care unit with fluid restriction, ventilation, and mannitol. Ventilation was continued for $36 \mathrm{~h}$ and full consciousness was regained soon after extubation. His aspiration pneumonia settled with intravenous antibiotics and he was allowed home after a stay of 12 days, with social work, occupational therapy, and psychiatric and psychological support.

At follow up 12 months later he had made a full neurological recovery with only a small residual memory loss.

Cases 2-7

A summary of cases 2-7 is given in the table.

\section{Discussion}

There are two major types of hanging: judicial hanging, in which the body drops a distance
Accident and Emergency Department, Derriford Hospital, Plymouth, United Kingdom M A Howell H R Guly

Correspondence to: M A Howell, Registrar, Accident and Emergency Department,

Derriford Hospital

Plymouth PL6 8DH

Summary of cases 2-7

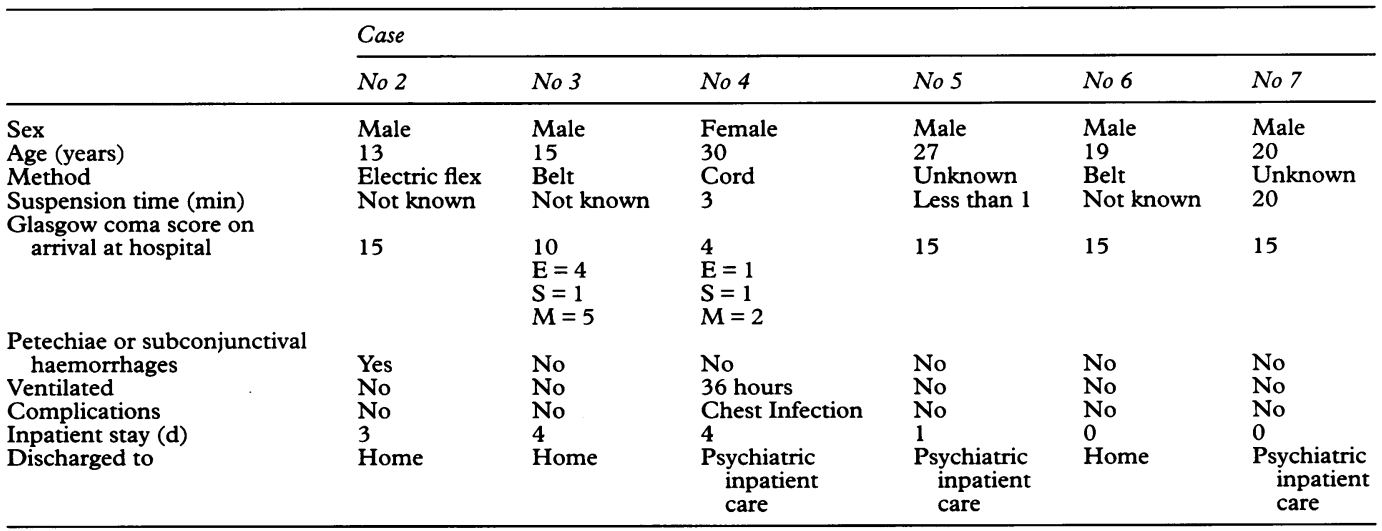

In all cases: (1) cervical spine $x$ rays were performed and were normal; (2) there was full neurological recovery; (3) psychiatric follow up was arranged. 
greater than the body height and death occurs by spinal cord transection, and non-judicial hanging, where there is no significant drop and injury occurs due to compression of neck structures. ${ }^{1}$ Non-judicial hanging may be fatal or non-fatal; in the latter case the term "near hanging" is used. The cases discussed were all examples of near hanging.

Deliberate self hanging is increasing in the United Kingdom, ${ }^{2}$ and in the USA around 3500 die each year from hanging or strangulation, placing the method as the third leading cause of suicide deaths behind firearms and poisons. ${ }^{3}$ Most instances are deliberate suicidal attempts but a few occur in association with erotic self stimulation. ${ }^{4}$ Near hanging is not uncommon and in the cases reported represented calls for help or parasuicide attempts.

The effects of hanging depend on the distance of fall to the ground. If this distance is greater than the body height (as in judicial hanging) then the head is forcefully torn away from the body with cervical spine fracture, spinal cord transection, and death. If the distance is small, as in non-judicial hanging, the mechanism of injury is that of ligature strangulation.

Circumferential neck pressure leads to venous obstruction and stagnant cerebral hypoxia and hence to loss of consciousness. Flaccidity and loss of neck muscle tone eventually allows arterial occlusion or airway collapse. The exact mode of death is not clear, and may include cardiac arrest as well as vascular occlusion and asphyxia..$^{5-7}$

Clinical features of non-judicial hanging include marks around the neck from the device used for the hanging, and also skin and subconjunctival petechial haemorrhages (Tardieu's Spots) due to increased venous pressure in the head. ${ }^{78}$ These, however, are not invariable features and were indeed only found in one of our seven cases. Injuries, including fractures, of the larynx are not uncommon but were not seen in any of our cases. Cervical spine injuries have not been reported in near hanging victims, and others have suggested that emergency cervical spine radiographs need not be performed unless there is a history of significant drop or neurological symptoms or signs of cord injury. ${ }^{9}$ They may, however, show surgical emphysema suggesting laryngeal fracture. In addition, the information available on initial presentation rarely allows cervical spine injury to be excluded. Advanced Trauma Life Support (ATLS) guidelines require cervical spine immobilisation and $x$ rays in all patients following major trauma ${ }^{10}$ and there is probably no justification for making an exception in these patients.

Pulmonary complications, including aspiration pneumonia, bronchopneumonia, and adult respiratory distress syndrome (ARDS), are a major cause of mortality and morbidity in near hanging victims, and were the major complication in two of our cases.

Long term survivors may display a variety of neuropsychiatric sequelae ranging from psychosis to amnesia, thought to be due to hippocampal sensitivity to anoxia. ${ }^{11}$ Case 1 had residual memory loss which may have been due to hippocampal hypoxia. Interestingly, psychiatric symptoms such as depression may remit spontaneously after attempted hanging. ${ }^{12}$

Initial management of near hanging victims follows the usual priorities of airway, breathing, and circulation (ABC). As cervical spine injury has not been reported, neck immobilisation is probably unnecessary in nonjudicial hanging victims. Hospital treatment should be in an intensive care unit and is generally supportive, being directed at airway control with endotracheal intubation, ${ }^{13}$ ventilation using positive end expiratory pressure (PEEP), and hyperventilation with supplemental oxygen to control intracranial pressure. ${ }^{14}$ Fluids are restricted and mannitol may be indicated. The role of prophylactic anticonvulsants, naloxone, calcium channel blockers, and steroids remains controversial. ${ }^{1} 61516$

Severe neurological defects may be reversible in cases of near hanging and all victims should be aggressively resuscitated and treated, irrespective of initial findings. ${ }^{14} 17$ This is well supported by the excellent outcomes in cases 1 and 4 despite their poor initial condition. Psychological sequelae are not so easily treated and all survivors of hanging incidents should receive support and follow up after discharge from hospital.

1 Rosen P. Barkin RM, Braen GR, Dailey RH, Hedges JR, Hockberger RS, et al. Emergency medicine. Concepts and clinical practice. St Louis: Mosby Year Books, 1992: 421-2.

2 Pounder DJ. Why are the British hanging themselves? $A m$ 7 Forensic Med Pathol 1993;14:135-40.

3 Statistical abstract of the United States, ed 96. Washington DC: US Bureau of the Congress, 1975.

4 Book RG, Perusal G. Sexual asphyxia: a lesser epidemic. Medicine Law 1993;12:687-98.

5 Iserson KV. Strangulation: a review of ligature, manual and postural neck compression injuries. Ann Emerg Med

6 McHugh TP, Stout M. Near hanging injury. Ann Emerg Med 1983;12:774-6.

7 Clarke MA, Feczko JD, Hawley DA, Pless JE, Tate LR, Fardal PM. Asphyxial deaths due to hanging in children. f Forensic Sci 1993;38:344-52.

8 Lowe L, Rapini RP, Johnson TM. Traumatic asphyxia. $f$ Am Acad Dermatol 1990;23:972-4.

9 Vander Krol L, Wolfe R. The emergency department management of near hanging victims. $f$ Emerg Med 1994;12:285-92.

10 Committee on Trauma. Advanced trauma life support instructors manual. Chicago: American College of Surgeons, 1994.

11 Medalia AA, Merriam AE, Ehrenreich JH. The neuropsychological sequelae of attempted hanging. 7 Neurol Neurosurg Psychiatry 1991:54:546-8.

12 Calache MJ, Achamallah NS. Spontaneous remission of depression after attempted suicide by hanging: a case 38:89-91.

13 Aufderheide TP, Aprahamian C, Mateer JR, Rudnick E, Manchester EM, Lawrence SW, et al. Emergency airway management in hanging victims. Ann Emerg Med 1994; manageme

14 Digeronimo RJ, Mayes TC. Near hanging injury in childhood: a literature review and report of three cases. Pediatr Emerg Care 1994;10:150-6.

15 Wohns RN, Kerstein MD. The role of dilantin in the prevention of pulmonary edema associated with cerebral prevention of pulmonary edema associated

16 Hosobuschi Y, Baskin DS, Woo SK. Reversal of induced ischemic neurologic deficit in gerbils by the opiate ischemic neurologic deficit in gerbils by
antagonist naloxone. Science 1982;215:69-71.

17 Brown VL, Espinosa J. Near hanging injuries: two case studies and an overview. $\mathcal{F}$ Emerg Nursing 1991;17:386-9. 